\title{
Notas sobre a articulação entre psicanálise, sofrimento psíquico e direitos humanos: elementos para uma ética do sujeito
}

Notes on correlating psychoanalysis, psychic suffering and human rights: elements for an ethics of the subject

Deborah Klajnman*1

Pedro Brocco*2

Este trabalho elenca algumas questões consideradas cru-ciais para uma articulação entre a Psicanálise e o Direito, em especial o campo dos Direitos Humanos, tomando como eixo da articulação a relação entre os conceitos de sofrimento psíquico, desamparo fundamental, ética da psicanálise e sujeito do inconsciente. Iniciando uma proposta de reflexão sobre o estatuto do Direito e do laço social a partir de um deslocamento de seu conceito de sujeito, a seguinte questão é colocada: o sujeito de direito, fundamentado na pessoa humana racional e consciente orientada pela tradição humanista e pela economia dos bens é ainda capaz de responder aos impasses no campo da política e do laço social? Partindo da afirmação de Lacan de que o objeto da psicanálise não é o homem, mas aquilo que lhe falta - não uma falta absoluta, mas a falta de um objeto, $o$ presente trabalho toma de antemão tal proposição para

*1 Universidade Estadual de Londrina - UEL (Londrina, PR, Brasil).

*2 Corpo Freudiano Escola de Psicanálise (Rio de Janeiro, RJ, Brasil). 
percorrer algumas linhas de abordagem crítica do discurso dos Direitos Humanos com o objetivo de realçar uma via epistemológica para além das críticas filosóficas e sociais e, assim, possibilitar a emergência de algo novo, que pode ser construido a partir da psicanálise: o impossível da universalidade das Declarações de Direitos Humanos e a consequente convocação do sujeito do desejo em extimidade ao sujeito de direito a partir do método clínico como via de abordagem do sofrimento que o humanismo, a ética clássica e o discurso dos Direitos Humanos recobrem.

Palavras-chave: Psicanálise, direitos humanos, sujeito de direito, sujeito do inconsciente

O objeto da psicanálise não é o homem; mas aquilo que lhe falta - não uma falta absoluta, mas a falta de um objeto.

\section{Introdução}

Após pouco mais de duzentos anos do aparecimento da literatura das grandes declarações de direitos humanos (Hunt, 2009), cujos destinatários seriam todos os humanos enquanto seres políticos, e pouco mais de cem anos do aparecimento da psicanálise, ${ }^{1}$ que se abre ao humano enquanto ser da linguagem e da fala e que tem, por isso, também um fundamento universal, seria possível aproximar esses dois campos discursivos para a invenção de novas práticas e formas jurídicas e institucionais? Pretendemos neste ensaio elencar algumas questões que nos parecem cruciais para uma articulação entre a Psicanálise a partir de Sigmund Freud e Jacques Lacan e o

${ }^{1}$ Âmbito que em sua prática e teoria também corrobora a ideia de que os seres humanos são políticos, o que pode ser verificado principalmente através da articulação lacaniana das noções de política e inconsciente ao afirmar que o "Inconsciente é a política!" (Lacan, 1966-67, p. 236). 


\section{ARTIGOS}

Direito, em especial o campo dos Direitos Humanos, tomando como nexo de tal articulação os conceitos de sofrimento psíquico, desamparo fundamental e o conceito de sujeito para a psicanálise.

Um dos principais pontos de apoio da teoria contemporânea do Direito é a noção de sujeito de direito: destinatário dos sistemas jurídicos e códigos legais, apto a articulá-los como titular dos direitos ali previstos, podendo propor demandas perante o Judiciário ou se fazer representar por aqueles que possuam capacidade postulatória. Em todos os casos, o sujeito de direito é correlato à pessoa. Pessoa dotada de um arcabouço jurídico consistente em uma trama de direitos (Villey, 2007, p. 98); pessoa dotada de corpo, dignidade, honra e outros bens jurídicos: enfim, pessoa a partir da qual se estrutura uma miríade conceitual e teórica que articula as bases do pensamento jurídico de um ponto de vista prático e filosófico. Em concomitância ao conceito de pessoa humana, está uma teoria da manifestação da vontade cujas raízes remontam à concepção de ser racional e consciente.

O sujeito do inconsciente, por outro lado, articulado pela psicanálise de modo especial por Jacques Lacan, porém já conceitualmente presente desde os primeiros estudos de Sigmund Freud (Berlinck, 2008a, p. 219), aponta para uma emergência ligada ao efeito do significante e à dinâmica pulsional em uma complexa trama articulada por Lacan entre o simbólico, o imaginário e o real.

A ordem jurídica, como ordem simbólica, se constitui como constelação e bateria significante a partir da qual o sujeito não é tanto o agente, como na concepção cogitativa cartesiana, mas "é determinado por uma função simbólica e que a posição resultante do sujeito com relação ao outro não é direta, mas mediada pelo sistema de regras e convenções do registro simbólico" (Berlinck, 2008a, p. 208).

Pretende-se neste trabalho iniciar uma proposta de reflexão sobre o estatuto do Direito e do laço social a partir de um deslocamento de seu conceito de sujeito de base. Em outros termos, coloca-se a questão: o sujeito de direito, fundamentado na pessoa humana racional e consciente, é ainda capaz de responder aos impasses no campo da política e do laço social? Em que medida o sujeito do inconsciente, estruturado a partir de um sistema de regras e convenções do registro simbólico, responderia a tais impasses?

Atentos aos estudos no campo da Psicopatologia Fundamental, procuraremos construir tais questionamentos no sentido de almejar a colocação do sujeito no mesmo campo de incidência dos impasses encontrados na clínica. 
Isto é, em que medida a redefinição do conceito de sujeito de base do Direito pode proporcionar novas configurações práticas no funcionamento do campo jurídico, através de uma técnica jurídica segundo a qual "a realização possível e responsável do sujeito enquanto ser de linguagem, no interior do laço social" (Pereira, 2019, p. 828), seria o objetivo precípuo da atividade jurisdicional, do acolhimento das demandas e conflitos às decisões judiciais?

Os conflitos no âmbito jurídico se instauram em torno de bens jurídicos, bens que Lacan aborda no seminário sobre a ética da psicanálise como sendo a dimensão de uma muralha poderosa na via do desejo (Lacan, 1959$-60 / 2008$, p. 274). Como então abordar a função dos bens que formam a base dos direitos humanos quando estes são a vida, a liberdade e a dignidade?

O século XX foi atravessado por uma série de questionamentos sobre a capacidade e a legitimidade do Direito ocidental para mediar conflitos sociais: acusado de burguês por anarquistas e comunistas, cooptado por regimes totalitários que promoveram o extermínio de milhões de seres humanos, o Direito continua a operar sobre as mesmas bases humanistas orientadas por uma psicologia ${ }^{2}$ herdeira do Renascimento e formuladora de uma concepção de base de sujeito de direito: a mesma base que é identificada como tendo oportunizado o surgimento do conceito de direitos subjetivos, componentes do patrimônio da pessoa humana substancializada. Michel Villey produziu trabalhos relevantes sobre o surgimento do conceito de direito subjetivo, estranho ao direito romano clássico, a partir da Idade Média. Segundo Villey, em Roma o que se chamava de jus não era o direito-poder de dispor e gozar de uma coisa, poder do credor, mas o vínculo, a própria obrigação, vinculum juris, a relação que liga objetivamente credor e devedor (Villey, 2005, p. 258). É razoável supor que o conceito de gozo esteja mais ligado ao conceito de direito subjetivo, por sua vez relacionado ao poder de usar e dispor de um direito, do que à vinculação do sujeito ao laço social.

Este trabalho proporá, ainda que de forma liminar, que a noção de sujeito de direito, entendida como pessoa racional, consciente e portadora de direitos, pode se enriquecer ao ser lida de forma concomitante com o referencial psicanalítico que articula a noção de sujeito do desejo ou do inconsciente, estruturado pela ordem simbólica no interior do laço social. Tal proposta traz inúmeros impactos, cujas envergaduras são imprevisíveis, porém

${ }^{2}$ Termo utilizado aqui em sentido amplo e literal: uma noção antropológica de sujeito vinculado à noção de alma e ao cogito cartesiano (cf. Berlinck, 2008a). 


\section{ARTIGOS}

pode trazer também mudanças significativas em relação ao funcionamento da administração de conflitos, a cargo do Poder Judiciário e, de forma mais ampla, ao estudo das instituições.

Pode-se sustentar de forma razoável que as questões envolvendo infrações a direitos humanos, como os crimes de genocídio, os crimes contra a humanidade (incluídos os crimes de homicídio, extermínio, escravidão, tortura, agressão sexual, entre outros) e os crimes de guerra ${ }^{3}$ envolvem uma carga imanente e considerável de sofrimento psíquico. Os direitos humanos, assim definidos os direitos aplicáveis a todos os seres humanos e cuja essência repousa nos princípios da dignidade da pessoa humana e da solidariedade, transnacionais e transfronteiriços, formam uma literatura jurídica que ganha relevo em fins do século XVIII, com as primeiras declarações de direitos do homem, e atingem seu apogeu em 1948, com a Declaração Universal dos Direitos Humanos, proclamada pela Assembleia Geral das Nações Unidas, após o terrível saldo destrutivo da primeira metade do século $\mathrm{XX}$ e, em especial, dos anos de governos nazifascistas.

Passadas algumas décadas desse cenário de repactuação do laço social em 1948, atravessamos uma quadra histórica que tem assombrado aquele momento de fundação do regime jurídico-político de construção de laços sociais pós-1945. Observa-se o surgimento, cada vez mais frequente, dos mesmos motivos ideológicos e os mesmos discursos, tomados em sua estrutura virulenta, que levaram ao surgimento dos nacionalismos extremados, cuja estrutura é a da adesão a um projeto de nação que elide a singularidade subjetiva. Neste sentido, tal projeto não se diferencia de adesões a coletividades, sejam elas quais forem: Freud, em Psicologia das massas e análise do Eu (1921/2011), propõe uma analogia entre a Igreja e o Exército como paradigmas de coletividades capazes de sugar e dissolver o sujeito, intuindo que partiria de tal confluência o programa mais perverso levado a cabo no século XX, o Estado nazista alemão, que a partir de 1933 promove a perseguição de partidos políticos e minorias sociais.

O Exército, no ideário nazista, é uma linha de força óbvia e manifesta; a Igreja há que se tomá-la mais por seus efeitos que pelo envolvimento efetivo de diferentes instituições, por mais que este tenha havido. Antes, porém, tratou-se de o próprio Estado nazista se construir em uma espécie de

${ }^{3}$ Tomamos aqui o rol de crimes de competência do Tribunal Penal Internacional, criado pelo Estatuto de Roma, de 1998, recepcionado pelo Direito brasileiro em 2002. 
hagiografia da figura do führer e de sua ação messiânica na História com a construção de um reino que duraria um milênio. Para tanto, era preciso também criar um imaginário segundo o qual a nação estaria acima de todos (com o mote Deutschland über alles), bem como de que o líder ou o guia se ocuparia da proteção e do desenvolvimento do corpo do povo, em uma analogia com o corpo biológico dos seres viventes - corpo que precisaria superar o que poderia aparecer em seu interior como estranho, elemento construído e identificado ideologicamente, móvel, mas que possui sua função na estrutura: aparecer como um significante que funciona como a marcação de uma diferença.

O funcionamento dos direitos do homem e do cidadão e, mais à frente, dos direitos humanos, possui como fator essencial a universalidade e a aplicabilidade a todos, sem exceção. Hannah Arendt já denunciou como grande paradoxo da política contemporânea a discrepância entre os esforços idealistas bem-intencionados, considerando inalienáveis os direitos desfrutados pelos cidadãos dos países civilizados, e a situação de seres humanos sem direito algum (Arendt, 1989, p. 312).

Entretanto, há que se reconhecer que o discurso dos direitos humanos traz em si, na potencialidade de uma aplicação universal, de difícil execução, um funcionamento antes de tudo pragmático-performativo segundo a concepção de J. L. Austin (1962), isto é, pretende-se fazer algo com as palavras, com uma de-claração, tornando claro um desejo em relação ao papel e função das instituições. A leitura das declarações, no entanto, em perspectiva com a dinâmica da realidade dos sistemas políticos atuais e pós-1945, mostra extrema dificuldade e mesmo uma impossibilidade de aplicação universal de tais direitos.

A função das declarações de direitos humanos, em uma inseparável e preciosa relação com o desejo, pode ser lida em Lacan, em uma curiosa passagem, quando afirma, em "Kant com Sade", "[...] considerando os direitos do homem sob a ótica da filosofia, vemos aparecer o que, aliás, todo o mundo agora sabe de sua verdade. Eles se resumem na liberdade de desejar em vão" (Lacan, 1962/1998b, p. 795; grifos nossos), para depois concluir: "Grande vantagem! - mas oportunidade de reconhecer aí nossa liberdade espontânea [...], e de confirmar que ela é mesmo a liberdade de morrer" (idem, ibidem). Parece-nos que Lacan estaria aí fazendo uma demarcação: para a filosofia, os direitos humanos se constituem na liberdade de desejar em vão. Mas para a psicanálise, seria também o caso de reconhecer aí o furo estrutural do sujeito e do que concerne à sua singularidade enquanto sujeito do desejo, submetido ao significante e sua incidência na relação do sexo 


\section{ARTIGOS}

(Lacan, 1969-70/1992, p. 135). Convocar o sujeito, aqui, seria convocá-lo no nível em que o significante apareça enquanto seu saber como verdade, ${ }^{4}$ o que torna um tanto paradoxal, mas apenas aparentemente, a relação da psicanálise com o universal.

Para Alain Didier-Weill, a questão dos direitos do homem deixa a psicanálise exposta a esta característica de efeito paradoxal, que ele define como um feixe de contradições (Didier-Weill, 2011). A primeira dessas contradições, segundo ele, é estrutural e está ligada ao fato de que, assim que se abre à fala, o sujeito é solicitado por duas injunções antinômicas que o dilaceram, a primeira das quais foi trazida por Freud com a frase Wo Es war, soll Ich werden - lá onde Isso estava, deve o Eu advir, ou, na tradução proposta por Dider-Weill, lá onde isso estava, tu deves advir! Esta frase fundamental freudiana imputaria ao sujeito, segundo Didier-Weill, uma capacidade de advir por meio da qual é suposta uma relação não impossível com a liberdade (idem, ibidem).

A segunda tópica freudiana, que promove o mote da advinda ou sobrevinda do sujeito, também traz a contradição a partir da qual se descortina um mandato completamente diferente, que Freud chama de supereu, que tende a sufocar o apelo do vir-a-ser, já que sua tendência é o seu contrário e significa para o sujeito um não podes advir! Não és livre para fazê-lo. Neste horizonte, o sujeito é solicitado por duas injunções antinômicas que o dilaceram, na medida em que alguma coisa o leva a responder simultaneamente "sim" à injunção que o convoca a comparecer, advindo lá onde a liberdade é possível e "sim" à outra voz que o declara não sendo livre (idem, ibidem).

O que tal dilacerante contradição nos mostra e se liga aos objetivos do presente ensaio, é o fato de ser impressionante que a dinâmica psíquica entendida por Freud traz já em seu funcionamento, independentemente de qualquer contexto político, "o que todo tirano é levado a dizer enquanto abole os direitos do homem: "Aqui não há liberdade, igualdade, fraternidade"” (idem, ibidem) ${ }^{5}$. Para Didier-Weill, assim, o inimigo dos direitos do homem

${ }^{4}$ Lacan afirma no seminário 17 como uma verdadeira mola propulsora o fato de o gozo separar o significante-mestre, na medida em que se gostaria de atribuí-lo ao pai, do saber como verdade. (Lacan, 1969-70/1992, p. 136; grifo nosso).

${ }^{5}$ Trata-se do mote da revolução francesa, cujos três significantes Liberdade, Igualdade e Fraternidade possuem grande importância na concepção das instituições republicanas e liberais da modernidade. Didier-Weill faz a articulação entre os três principais significantes da revolução francesa e a transmissão da psicanálise, assim como Paolo Lollo (2015). 
não seria a criação de partidos políticos fascistas, mas a voz do supereu, uma espécie de inimigo interior e perseguidor íntimo que condena o sujeito sem processo e sem direito à ampla defesa e contraditório, fazendo com que o sujeito aceite o resultado de seu processo sem apelação, lembrando nesta dinâmica o personagem K., de $O$ Processo, de Franz Kafka.

A angústia sentida pelo sujeito mesmo quando é levantada a censura que lhe dizia "não", para Didier-Weill, indica que a liberdade que possa acometê-lo neste momento, quando não há mais culpa, seria a ocasião de um medo radical diante da possibilidade de procriação de uma nova existência:

Que seja sempre novo o brotar da existência como tal, eis o mistério do que há de mais real no humano. $\mathrm{O}$ enigma que a psicanálise revela aqui é que o sujeito humano pode assustar-se mais com o apelo a dizer "sim" ao direito de existir do que com a injunção mortífera de dizer 'não' a este direito. (idem, ibidem)

Seria o caso então de sustentar que há determinados tempos históricos decisivos em que uma coletividade decide dar um passo atrás no momento em que se depara com dizer um "sim" à vida em abundância para o maior número possível de pessoas, apostando no brotar de uma nova dinâmica de laço social? A constatação de tal dinâmica no coração de cada sujeito pode funcionar como indício para a compreensão de grandes movimentos de massa que exploram a faceta da voz superegoica, amplificando-a no funcionamento político de máquinas mortíferas de guerra - à liberdade.

A elaboração do que seria tal liberdade, tomando aqui o termo elaborar no sentido freudiano de perlaborar, isto é, trabalhar, mas também formar elos de trabalho, de ligação e de sentido, é uma aposta em direção à finalidade humana, pois separá-la da finalidade humana é desconectar o trabalhar do amar, em seu enlaçamento com o outro, enquanto ação externalizada voltada ao amor e ao trabalho - ação que une a dimensão pulsional-sexual à dimensão simbólico-linguageira —, um dos sentidos possíveis, mas não o único, de tradução e transmissão do conceito de "direitos humanos".

\section{Liberdade de desejar em vão - filosofia}

A crítica ao discurso dos direitos humanos tem sido recorrente e acompanha o surgimento dos grandes movimentos de luta dos trabalhadores, que culmina no aparecimento da tradição marxista. Marx, então estudante 
de Direito, inicia sua atividade teórica e política escrevendo na Gazeta Renana, logo depois se tornando seu redator (1842-1843). Nesse período, em seu célebre artigo sobre o furto da lenha e a situação dos camponeses, influenciado por Hegel, Marx começará a delinear a hipótese da aproximação do Estado aos interesses privados — o Estado a serviço dos proprietários e seus interesses privados (Hobsbawm, 2007), cuja lógica se escamoteia num discurso pretensamente universalista e neutro. Eis o projeto de uma crítica ao Estado como ideologia que se tornará cada vez mais explícita, até chegar à Crítica da filosofia do direito de Hegel Introdução, quando Marx afirmará, a partir do paradigma estabelecido por Hegel da dialética do senhor e do escravo, que o proprietário privado é egoísta e covarde; somente os privados de tudo, os que não têm nada a perder, são capazes de coragem, energia revolucionária e identificação com os interesses universais (Löwy, 2017).

Ao aproximar os interesses privados da forma de Estado, que naquele momento reprimia os camponeses pobres que colhiam a lenha de propriedades privadas a partir de um costume ancestral, segundo o qual a lenha era de uso comum, Marx lança as bases para a crítica do Estado como ideologia. As declarações de direitos humanos, neste sentido, seriam vistas como pura ideologia, textos sem alcance prático a não ser o de escamotear o funcionamento e o alcance do Estado burguês.

A tradição de leitura da função dos direitos humanos como um texto "vazio", com o objetivo de servir aos interesses de uma minoria privilegiada, possui uma continuidade que aqui vai de Marx e passa por Hannah Arendt, Giorgio Agamben e chega propriamente ao campo do Direito pelos escritos de Michel Villey.

Villey, filósofo do Direito, estabelece sua crítica ao discurso dos direitos humanos com um livro do início dos anos 1980, Le droit et les droites de l'homme (Villey, 2007). dedicado a apontar para o depauperamento do Direito enquanto arte jurídica derivada dos romanos e cuja raiz remonta a Aristóteles.

Para Villey, os direitos humanos são um sinal de confusão epistemológica e representam um triste horizonte que foi gestado desde a filosofia medieval, em uma progressão paulatina rumo a um mundo esvaziado das mais altas construções humanas, entre elas a filosofia e a jurisprudência clássica, expressões de uma vida irremediavelmente perdida. A despeito de sua peculiar erudição, o livro de Villey é a expressão de um conservadorismo que procura 
a ordem harmoniosa da polis grega onde não é mais possível vivê-la. Logo no início de seu livro, após dedicá-lo ao papa João Paulo II, ${ }^{6}$ Villey escreve que o direito é um tema eminentemente grego: "os poetas, os trágicos, os filósofos são como que obcecados pela descoberta, no seio do cosmos, das cidades, ou da história humana, de uma ordem harmoniosa" (Villey, 2007, p. 33), entendendo que o resgate desta ordem pelo direito seria uma volta ao bom caminho. Tal volta ao "bom caminho" seria dada por intermédio de Aristóteles e ao que este escreveu sobre o direito na Ética a Nicômaco. Seria, portanto, uma volta à ética aristotélica, em relação à qual a psicanálise nos adverte que se trata de um laço social enodado de forma muito peculiar pelo discurso do mestre, já deslocado desde o advento da ética utilitarista, influenciadora direta de Freud para a formulação da psicanálise (Lacan, 1959-60/2008, p. 23).

Slavoj Žižek, em Contra dos direitos humanos, escreve um interessante ensaio que estabelece as principais linhas críticas ao discurso dos direitos humanos para, ao final, fazer um giro que interessa a este trabalho e à sua articulação com a psicanálise. Com base em Jacques Rancière, Žižek reconhece que a interpretação sintomática marxista dos direitos humanos universais como expressão ideológica burguesa para exercício de domínio político é apenas uma metade da história. A outra metade consiste em uma questão mais difícil, a da própria emergência da forma da universalidade. Os indivíduos experimentam a universalidade abstrata em suas vidas de forma cada vez mais intensa, e Žižek dá o exemplo da profissão, a partir da qual nos experimentamos como indivíduos que não nasceram naturalmente ou diretamente em seu papel social, o que nos leva a nos relacionarmos com o destino de forma contingente e deslocados de uma particularidade ontológica imutável — assim como não faria sentido atribuir a um camponês medieval a situação de uma profissão. A mesma voragem universal se observa, já desde os apontamentos de Marx, com o fetichismo da mercadoria, em que os indivíduos se experimentam em uma sociedade onde predomina a troca de mercadorias "fazendo referências a si mesmos e aos objetos que encontram como personificações contingentes de noções universais abstratas" (Žižek, 2010, p. 26).

${ }^{6}$ Apesar de ter recorrido com frequência ao discurso dos direitos humanos, foi sob o pontificado de João Paulo II que foram realizadas perseguições ao clero que se dedicava ao tema da desigualdade social e à busca por justiça aos mais pobres, sobretudo na América Latina, com a atuação do futuro papa Joseph Ratzinger à frente da Congregação da Doutrina da Fé, que com práticas inquisitoriais perseguiu, suspendeu e puniu diversos sacerdotes que não seguiam os preceitos tradicionais da Igreja, em uma atuação francamente conservadora. 
Assim, segundo Žižek, a forma nunca é mera forma, mas envolve uma dinâmica própria, que deixa traços na materialidade da vida social: foi a liberdade formal burguesa que permitiu a articulação das demandas políticas do sindicalismo e do feminismo. Do ponto de vista jurídico e político, haveria uma perene dialética, uma tensão entre duas narrativas em que nenhuma delas é capaz de nos fornecer toda a verdade. Mas Žižek muito bem articula, a partir de trabalhos de Jacques Rancière, que mais interessante do que apenas afirmar uma articulação do mundo e da vida apropriada por aqueles que estão no poder para servir aos seus interesses particulares e fazer dos súditos dóceis peças na engrenagem social, é o processo oposto segundo o qual "o que é originalmente um edifício proposto pelos colonizadores é tomado em seu conjunto subitamente pelos súditos como uma maneira de articular suas queixas 'autênticas"' (idem, ibidem).

Se, como nos mostra a psicanálise, e de forma muito clara com Lacan, o universal não é propriamente "o homem", "o humano", mas a falta de um objeto, a gramática dos direitos humanos, em tensão com os "direitos políticos nacionais", tende a cada vez mais se constituir como a gramática da política por excelência, a ser observada pela dinâmica legiferante nacional, mesmo quando presentes os retrocessos políticos da última década, que podem ser lidos como um verdadeiro sintoma.

\section{Sujeito do inconsciente e direitos humanos}

Ao visar a garantia dos direitos iguais para todos os seres humanos, a Declaração Universal dos Direitos Humanos (1948) coloca em lugar de destaque, tanto em seu registro escrito, como em seu discurso mais amplo e corrente, as minorias sociais e demonstra (ou parece demonstrar) que defender o universal implica reconhecer as diferenças de tal forma que se não as transforme em desigualdades, tanto sociais quanto de direitos. A declaração especifica algumas distintas categorias sociais, assim como explicita o emblemático trecho do Artigo $2^{\circ}$ :

[...] toda pessoa tem capacidade para gozar os direitos e as liberdades estabelecidos nesta Declaração ${ }^{7}$, sem distinção de qualquer espécie, seja de raça, cor, sexo, língua,

${ }^{7}$ Esta é nossa escolha de tradução para o trecho: "Everyone is entitled to all the rights and freedoms set forth in this Declaration [...]". 
religião, opinião política ou de outra natureza, origem nacional ou social, riqueza, nascimento, ou qualquer outra condição. ${ }^{8}$

No entanto, não podemos nos furtar de ponderar e analisar as raízes histórico-sociais dos Direitos Humanos que culminam e possuem efeitos diretos em nosso tempo. Ramalho (2009), a partir de outra lógica, complementa o tripé da Revolução Francesa, que marca, a partir de 1789, o nascimento de uma nova sociedade e servirá como base para a Declaração dos Direitos Humanos. Segundo ele, principalmente a partir da hegemonia da lógica neoliberal podemos considerar uma passagem dos preceitos Liberdade, Igualdade e Fraternidade para Liberdade contratual e de negociar, fundamental para o capitalismo; Igualdade jurídico-formal, que possibilita pensar que todos são - ou deveriam ser — iguais perante a lei, porém não que as condições e oportunidades são iguais para todos; e a Fraternidade como laços de solidariedade com o objetivo de fornecer uma espécie de coesão social, que também não teria outro fim que a produção capitalista.

Neste sentido, o jurista e psicanalista sugere, a partir e talvez de uma outra maneira àquela proposta por Marx, que considera a divisão social opondo os dominados aos dominantes ou os opressores aos oprimidos, uma divisão entre as categorias de incluídos e excluídos. ${ }^{9}$ A primeira abarcaria tanto os opressores quanto os oprimidos e a segunda aqueles que não fazem parte nem mesmo da classe de oprimidos. Para corroborar com este argumento, ele aponta para o crescente deslocamento do uso de termos políticos para econômicos, em que podemos sublinhar como exemplo paradigmático o deslizamento do termo cidadão para consumidor, isto é, segundo este ponto de vista, somente são considerados cidadãos aqueles que consomem (direito do consumidor, direitos para o consumidor).

Para Ramalho (2009) é também em um tripé que o neoliberalismo se assenta: competição, eficiência e desigualdade. O primeiro possui valor de lei, mas uma lei que não considera limites éticos, jurídicos e políticos; o segundo, instaurado enquanto técnica, estaria funcionando a serviço da competição, estabelecendo a ideia de que não basta competir, é preciso vencer

${ }^{8}$ Assembleia Geral da ONU (1948). "Declaração Universal dos Direitos Humanos" (217 [III] A). Paris. Recuperado em 6 abr. 2020 de: <https://www.un.org/en/ universal-declaration-human-rights/>.

9 Poderíamos supor uma relação da categoria de excluídos com a de "lupemproletariado", cunhado por Marx na obra O Dezoito de Brumário de Luis Bonaparte (1852/2011). 
a competição; e o terceiro, que favorece a competição e é preconizada como princípio fundamental do neoliberalismo. Enodadas em uma lógica que podemos compreender de forma borromeana, a desigualdade favoreceria a competição eficiente, tendo como fim o desenvolvimento do mercado. Segundo este tripé estruturado por tal lógica competitiva, a sociedade estaria estruturada entre uma minoria de vencedores, que também poderíamos chamar de opressores; uma maioria de perdedores ou oprimidos, agrupando a categoria de incluídos e aqueles que não estão nesse jogo competitivo, que não conseguem nem mesmo chegar à categoria de perdedores, os excluídos (Ramalho, 2009).

Logo, diferente do que o discurso dos direitos humanos pode sugerir, o fato de haver exclusão social não é um acidente de percurso, mas a própria espinha dorsal do modelo (neo)liberal. Sendo a exclusão, portanto, endêmica ao modelo neoliberal, podemos deduzir que a própria raiz dos direitos humanos é, em sua disposição, excludente e não igualitária, como a sua roupagem promete. Aqueles que, portanto, denominamos excluídos são uma categoria social produzida pela própria estrutura do neoliberalismo, alimentada pelo modo de produção do capital e do qual depende a sua sobrevivência. Este sistema, engendrado a partir de uma lógica que se inicia desde o liberalismo da Revolução Francesa, por seu turno, possuiu como documento mais importante de toda Revolução a Declaração dos Direitos do Homem e do Cidadão (1789), que é a principal fundamentação da atual Declaração dos Direitos Humanos, esta que em seu discurso aponta defender os mesmos excluídos ao reconhecer algumas de suas diferenças.

Aqui convém recuperar uma citação de Lacan que, ao citar Marx, parece ir ao encontro da ideia acima:

[...] é a partir do inconsciente e do sintoma que ele pretende prorrogar a grande Revolução: é a partir da mais-valia descoberta que ele precipita a consciência dita de classe. Lênin, ao passar ao ato, não obteve nada além do que chamamos de regressão em psicanálise: ou seja, os tempos de um discurso que não foram sustentados na realidade, antes de mais nada, por serem insustentáveis. (Lacan, 1970/2003b, p. 422)

Seguindo este exame, também a partir da ótica lacaniana, podemos concluir que a Declaração Universal dos Direitos Humanos, sendo diretamente derivada da Revolução Francesa, não possui um caráter revolucionário, o que quer dizer que ela não propicia uma transformação social, pelo contrário, ela conserva um "retorno ao mestre/senhor que tem a arte de torná-las úteis" (idem). 
$\mathrm{Na}$ contramão do discurso do mestre, o discurso analítico ensina a interrogar os imperativos superegoicos do eu, paradoxais e frequentemente estranhos (Lacan, 1959-60/2008). Estes imperativos podem ter relação direta com o ponto de onde começamos este item: as minorias sociais, a quem também podemos aproximar a categoria de excluídos. Para examinar esta articulação, num primeiro momento, realizaremos alguns breves comentários sobre a noção de minorias sociais, para posteriormente nos determos um pouco mais detalhadamente no exame da noção de identidade, uma vez que uma não parece estar desvinculada da outra. Esta última, referida principalmente enquanto identidade social e as suas distintas categorias.

Diferente do que a expressão pode sugerir, como sabemos, a ideia de minorias sociais ${ }^{10}$ não expressa quantidade, mas uma situação de desvantagem social. Podem ser considerados grupos étnicos, culturais, linguísticos, religiosos, de gênero e de sexualidade como minoritários. No Brasil ainda poderíamos incluir como grupos minoritários a população negra e indígena. Estas distintas classes com origens variadas possuem identidades sociais formadas ou em formação e nelas, algumas vezes, grande potencial de luta política. Essa é uma primeira conjectura com a qual nos deparamos: as catego294 rias sociais representadas acima, e tantas outras, agregam múltiplos indivíduos em um grupo social específico, um grupo de idênticos, formando assim uma identidade social.

No entanto, num segundo momento é fundamental assinalar que a psicanálise caminha por outra direção, ela vai de encontro ao conceito de identidade, primando pela noção de "identificação", trabalhada tanto por Freud quanto por Lacan. Para compreender essa diferença é importante tentarmos aprofundar o que a psicanálise tem a contribuir neste campo.

Se por um lado, o planeamento imaginário possibilita a passagem do “corpo despedaçado" (Lacan, 1949/1998a) para uma unidade corporal, ele também antecipa a própria morte do sujeito; ideia da qual concluímos que, se por um lado o imaginário é desejável, por outro ele é destrutível. O valor dos diversos agrupamentos sociais e das suas respectivas lutas, que possuem como

${ }^{10}$ Segundo o sociólogo Mendes Chaves (1970) "[A palavra minoria se refere a] um grupo de pessoas que de algum modo e em algum setor das relações sociais se encontra numa situação de dependência ou desvantagem em relação a um outro grupo, 'maioritário', ambos integrando uma sociedade mais ampla. As minorias recebem quase sempre um tratamento discriminatório por parte da maioria" (p. 149). 


\section{ARTIGOS}

base a noção compartilhada de certa "identidade", não exclui a possibilidade de que a imagem de si possa ter a função também de, em alguma medida, conduzir o ser humano para o seu próprio apagamento e morte enquanto sujeito, território que se apresenta um tanto quanto paradoxal.

Prevalecendo a noção de "identificação" ao invés da de "identidade", quer a psicanálise, nos parece, atentar para que a identidade propriamente dita não exista; de acordo com Freud, o sujeito é constituído não por diversas identidades, mas por diversas identificações, e que não é da alçada do âmbito analítico o trabalho com a noção de identidade. Uma análise se ocupa, a partir das vozes do inconsciente, em questionar as "imagens do eu", possibilitando um descolamento do automatismo de repetição dos percursos tantas vezes já trilhados e transformados em gozo, fonte de produção de sintomas e sofrimento. Em outras palavras, a homofonia lançada por Lacan para se referir à torção do discurso do inconsciente, que ele nomeia de mestre, maître, para o discurso analítico, m'être, nos permite compreender esta passagem.

\section{Os direitos humanos no século XXI: por uma ética do sujeito (e do desejo)}

A História da humanidade, do ponto de vista hegeliano-marxista, está calcada no conflito: senhor contra escravo, explorados contra exploradores, capital contra trabalho. Contudo, a História humana também se mostra como História de permanente colonização: colonização de linguagem e de texto. Lacan afirma que o têxtil é primeiramente um texto (Lacan, 1959-60/2008, p. 272), para depois afirmar que o homem enquanto tal, homem com direitos, começa a se individualizar a partir do momento em que detém panos com furos nos quais ele introduz a cabeça e em seguida os braços, por meio dos quais ele começa efetivamente a se organizar como trajado, como tendo necessidades que foram satisfeitas. Mas o bem avança em outra direção: não se detém apenas na via da necessidade: há outra coisa além de seu valor de uso, há sua utilização de gozo. Em outros termos o bem se articula no nível em que o sujeito pode dele dispor: "dispor de seus bens é ter o direito de privar os outros de seus bens" (Lacan, 1959-60/2008, p. 274). Daí Lacan vai afirmar que a dimensão do bem (do gozo) levanta uma muralha poderosa na via do desejo, e que o repúdio radical de certo ideal do bem é necessário para chegar a apreender a via que se desenvolve na experiência analítica. Pois bem: a partir destas indicações, é possível afirmar que, apesar das declarações dos direitos humanos historicamente consideradas em seu contexto de 
aparecimento, foi possível a construção de um arcabouço jurídico-institucional capaz de empreender um repúdio radical do ideal do bem? Aqui, parece-nos que Lacan fala do ideal do bem fundado pelo utilitarismo, isto é, o máximo de utilidade para a maioria, o máximo de bens para a maioria como busca da felicidade sancionada socialmente. Ora, Lacan (1959-60/2008) observa, ainda no discurso sobre a função do bem, que:

O âmbito do bem é o nascimento do poder. A noção de disposição do bem é essencial, e se a colocamos no primeiro plano vem à luz tudo o que significa a reivindicação do homem que conseguiu, num certo momento de sua história, dispor de si mesmo. Não fui eu, mas Freud quem se encarregou de desmascarar o que quer dizer isso na efetividade histórica. Dispor de seus bens, todos sabem que isso se acompanha de certa desordem, que mostra suficientemente sua verdadeira natureza - dispor de seus bens é ter o direito de privar os outros de seus bens. (p. 274)

A colonização permanente, que atesta o caráter parasitário da linguagem em relação ao ser, de tal modo que só seja possível conceber o ser a partir dela, é o tema do ensaio de Manoel Tosta Berlinck intitulado "Insuficiência imunológica psíquica" (2008b), onde o autor analisa o mais amplo e eficaz genocídio produzido pelo Ocidente moderno, a conquista da América espanhola, ${ }^{11}$ a partir da obra do dominicano Bartolomé de Las Casas, para construir sua hipótese da insuficiência imunológica psíquica dos povos nativos americanos, nestes termos:

Para Freud, histeria, obsessão, perversão etc., são modos de subjetivação, ou melhor, são a subjetividade, pois o sujeito se constitui somente por essa via. É por isso que é possível se falar de uma psicopatologia fundamental, pois o que não institui a subjetividade pela via psicopatológica produz o extermínio.

Entretanto, apesar dessas descobertas tão importantes, ainda estamos longe de compreender por que certas populações são mais vulneráveis do que outras a ataques virulentos, e por que se deixam destruir sem esboçarem nem sequer uma defesa manifesta. Que todos somos portadores de um desamparo originário, responsável inclusive por uma insuficiência constitutiva do aparelho

${ }^{11}$ Para Berlinck (2008b), "trata-se, indiscutivelmente, do maior, mais amplo e eficaz genocídio de que se tem notícia no Ocidente moderno, sendo bem maior do que o praticado pela Alemanha nazista com judeus e ciganos europeus" (p. 180). Segundo os relatos lascasianos, o número aproximado de mortos, apenas nas primeiras décadas de colonização espanhola, girava em torno de 15 milhões de indivíduos. 


\section{ARTIGOS}

psíquico, não se discute. Essa é uma importante descoberta freudiana. Que a subjetividade humana se manifesta, ainda que de forma evanescente, pela via psicopatológica, também não se discute. Mas ainda que sejamos todos iguais, há uns que são mais iguais que outros constituindo, assim, um enigma que pede imperativamente um esforço de pesquisa e de compreensão. A esse desamparo adicional que, como uma paixão, expõe o sujeito ao extermínio é que estou denominando de insuficiência imunológica psíquica. (Berlinck, 2008b, p. 182)

Berlinck (2008b) sustenta que em relações sociais comunitárias, onde há "ausência de individualismo" (p. 183) e onde vigoram normas sociais rígidas a partir das quais as pessoas nascem para ocupar posições fixas previamente determinadas, haveria um espaço diminuído ou inexistente de liberdade e consequente margem para a invenção de novos laços e possibilidades de relações sociais, diminuindo também a margem para deslocamentos psíquicos, tornando toda a comunidade vulnerável à colonização: “com a persistência de ataques externos virulentos, tendem a se salvar os membros que abandonam os princípios da comunidade adotando uma atividade que se expressa por movimentos físicos e psíquicos" (p. 184). Para Berlinck, o processo colonizador enquanto um ataque externo virulento depende, portanto, da insuficiência imunológica psíquica da comunidade colonizada, e tal processo colonizador pode ser tanto no caso de vírus e outras doenças que se instalam nos corpos quanto de populações que invadem territórios pertencentes a outras populações, de modo que todo processo de colonização envolve um grau de complexidade que necessita de cuidadosa análise (idem, ibidem).

Concluindo seu texto, que vai da colonização da América espanhola aos vietcongues e aos que conseguiram se implicar em deslocamentos físicos e psíquicos que atenuaram a insuficiência imunológica psíquica, Berlinck (2008b) evoca a figura da mãe fálica e sua capacidade de produzir nos filhos um desconhecimento de sua capacidade de se cuidar e se proteger (pp. 190-191). Um dos pontos centrais na teoria lacaniana é o de que o desejo só consegue satisfação sob a condição de fazer uma renúncia parcial, na medida em que a criança renuncia a ser o objeto exclusivo do desejo da mãe (Lacan, 1957-58/1999, p. 298). Em outras palavras, o texto de Berlinck nos diz que ao realizar a renúncia parcial e ao tornar o desejo demanda, significado pela existência do significante, a criança opera o deslocamento significante em direção ao seu desejo, diminuindo sua insuficiência imunológica psíquica para o restante de sua vida, evitando assim que desenvolva "uma disponibilidade para se entregar ao outro e esse é um campo fértil para a colonização 
perniciosa, um campo no qual pode vicejar a insuficiência imunológica psíquica" (Berlinck, 2008b, pp. 190-191).

$\mathrm{O}$ ensaio de Berlinck tece uma bela e instigante analogia entre a teoria psicanalítica e a dimensão social e histórica, tendo como eixo a noção de sujeito. Sua hipótese da insuficiência imunológica psíquica, ademais, parece coincidir com a hipótese de Tzvetan Todorov para o desaparecimento das civilizações maia e asteca: "em maia, a mesma palavra significa profecia e lei" (Todorov, 2010, p. 91); "tudo acontece como se, para os astecas, os signos decorressem automática e necessariamente do mundo que designam, em vez de serem uma arma destinada a manipular os outros (...)" (p. 126).

O campo semântico do ataque colonizador virulento, tanto para se referir à violência política quanto à presença de agentes patógenos virais, aplica-se ao caso da colonização americana desde o seu início. Naquele momento, o discurso colonizador era munido pela ética aristotélica traduzida catolicamente por Tomás de Aquino.

Orientada pelo que Lacan denominou de discurso do mestre, a ética aristotélica não é mais capaz de fundamentar a vida política e informar os contornos jurídicos das sociedades contemporâneas sem causar sofrimento psíquico, pois tende a eliminar a singularidade do sujeito em seu discurso, remetendo-a a padrões cujas linhas de força são as da verticalidade e a da padronização comportamental, escondidas sob o significante "humano". ${ }^{12}$

A utilização do discurso do mestre pela ciência, movimento já identificado por Lacan, promove uma subversão do discurso do mestre. Uma série de gadgets invade a vida, com sons e imagens entrando pelos olhos e ouvidos dos sujeitos, também neste movimento os alienando de sua singularidade e de seu saber (Lacan, 1969-70/1992, p. 157) ${ }^{13}$. Palavras são forjadas neste novo regime discursivo, como os memes e os virais, compartilhamentos

${ }^{12}$ Cabe lembrar aqui da frase, cotidianamente falada no Brasil: "direitos humanos para humanos direitos", que traz em si uma perversa promessa de aniquilamento de alteridades.

${ }^{13}$ No trecho do Seminário 17 denominado "Conversa nos degraus do Panteão", Lacan responde às questões colocadas por alguns participantes de seu seminário quando a Faculdade de Direito da rua Saint-Jacques estava fechada. Aqui, Lacan se manifesta sobre a pergunta "Então, onde é que o senhor situa o proletário?", citando os gadgets como ciência "de algum modo objetivada", capaz de despojar o saber do proletário/explorado. Esse trecho parece fazer referência direta ao que Lacan denominou discurso do capitalista, a subversão do discurso do mestre antigo para o do mestre moderno, que não faz laço e promete uma série de objetos forjados pela ciência prontos para a satisfação e o gozo imediato dos sujeitos. 


\section{ARTIGOS}

imagéticos-afetivos que promovem padronizações comportamentais segmentadas e variáveis.

Em que medida o sujeito do desejo e do inconsciente aí se elide e como reencontrar sua via?

Ao tomarmos a arte trágica de Sófocles, cara tanto ao âmbito do direito quanto ao da psicanálise, percebemos que Antígona evoca o direito natural e costumeiro de enterrar seu irmão Polinices, direito objetado pelo decreto de Creonte. A partir da posição desejante de Antígona, uma questão pode ser colocada: seria possível conceber os Direitos Humanos a partir do duro desejo de durar, isto é, desejo de desejar (Lacan, 1959-60/2008, p. 362)? Se em grande medida o Direito ocidental se centra no serviço dos bens, é possível que os Direitos Humanos, lançados pelo sujeito do desejo, possa ultrapassar este limite, o limite do serviço dos bens, do primum vivere? Pois Antígona, assim como Édipo, avançam esse limite. Lacan afirma que Édipo vai até o me phynai do verdadeiro ser-para-a-morte (idem, ibidem). Contudo, para além da morte física dela mesma e do próprio irmão, a relação íntima do desejo de Antígona e o que ele mantém com o significante "meu irmão" retira Polinices da pura ordem natural do mundo e o estende para além das leis impostas pela ordem social vigente (Santana, 2019, p. 180):

Meu irmão, ele é tudo o que quiserdes, o criminoso, ele quis arruinar os muros da pátria, levar seus compatriotas em escravidão, ele conduziu os inimigos para os territórios da cidade, mas enfim, ele é o que é, e o que está em questão é prestar-lhe as homenagens funerárias. Certamente, não tem ele o mesmo direito que o outro, vós podeis muito bem contar-me o que quiserdes, que um é o herói e o amigo, que o outro é o inimigo, mas eu, respondo-vos que pouco me importa que isso não tenha o mesmo valor aqui embaixo. Para mim, essa ordem com a qual vós ousais intimidar-me não conta nada, pois, para mim, em todo caso, meu irmão. ${ }^{14}$

Neste âmbito, ao evocar a psicanálise enquanto instrumento para pensar a singularidade, fazemos referência à teoria dos discursos elaborada por Lacan (1969-70/1992) e arriscamos examinar o que denominamos discurso do direito, seguido também pelo discurso dos direitos humanos, enquanto derivados do discurso do mestre. Apoiado no mesmo fundamento aristotélico,

${ }^{14}$ Lacan (1959-60/2008), no Seminário, livro 7: A ética da psicanálise, comenta que Lévi-Strauss, ao reler Antígona, se expressou falando que Antígona, diante de Creonte, se situa como a sincronia oposta à diacronia, p. 336. 
na tentativa de incluir todos e visando o Bem, amortecendo ou acabando com o mal-estar, não ultrapassa o campo do serviço dos bens e do primum vivere.

De forma universal, isto é, não segregativa, o discurso dos direitos humanos estabelecido textualmente em forma de declarações, porém amplamente difundido no discurso cotidiano, promete para todos, além de direitos denominados "básicos", impedir sofrimentos através de enunciações como ninguém deve...

\section{Considerações finais}

$\mathrm{Na}$ tentativa de articulação entre o discurso analítico e os direitos humanos, encontramos em Freud (1919[1918]/1969), numa aproximação entre o direito público e a psicanálise, ao defendê-la enquanto um direito, a seguinte afirmação: "o pobre deve ter tanto direito à assistência para sua mente, quanto dispõe agora do auxílio oferecido pela cirurgia a fim de salvar a sua vida [...]" afinal de contas, "[...] as neuroses ameaçam a saúde pública não menos do que a tuberculose" 15 (p. 180). Ao nosso ver, a importância de uma declaração deste tipo, proferida por aquele que criou a psicanálise, principalmente ao incluir e nomear, diferentemente do que mostram as raízes das declarações burguesas, os "pobres", é inquestionável. No entanto, Lacan articula, também a partir de Freud, mas ao mesmo tempo trazendo o ângulo da segregação implícita à formação do laço social, a problematização da ideia de direitos a todos considerando a noção de castração, de impossível.

As expressões "toda pessoa tem direito..." e "ninguém será...", recorrentes na Declaração de 1948, demonstram a exclusão da impossibilidade do universal. Neste imperativo em que todos possuem direitos e ninguém pode ficar de fora, a psicanálise enquanto ferramenta de reflexão nos possibilita afirmar que a própria estrutura da linguagem e do discurso, assim como o

15 Trata-se de parte do discurso proferido por Freud no V Congresso Psicanalítico Internacional que, segundo Danto (2019) convocava uma renovação social, assim como ela mostra em seu livro As clínicas públicas de Freud, apontando para este chamado de Freud articulado ao movimento histórico-social que ficou conhecido no pós-guerra como Viena Vermelho. Esta conjuntura é trabalhada detalhadamente no capítulo exclusivo sobre o ano de 1918, tratando do contexto histórico e político da Psicanálise freudiana em seu caráter revolucionário, que contava com apoio de psicanalistas como Sándor Ferenczi, Ernest Jones, entre outros. 
laço social, como nos acena Lacan (1974/1993) são segregativos. Isto é, por uma questão estrutural, "todos" e "ninguém" não podem entrar. No entanto, pode-se levantar uma questão: mesmo com a sua origem histórico-burguesa e suas limitações sociais, o discurso dos direitos humanos não faz barreira ao gozo segregativo ao qual nos impõe cada vez mais o capitalismo neoliberal? Como afirma e antevê Lacan (1969-70/1992): "Nunca se terminou completamente com a segregação. Posso dizer a vocês que ela vai sempre reaparecer com mais força" (p. 189). O Direito e o discurso dos direitos humanos seriam representados, assim, na dimensão da Lei: dimensão terceira e simbólica que aponta também para a impossibilidade e a castração.

A partir dessas considerações pontuamos que, se por um lado, o analista é orientado pela estrutura, tanto enquanto linguagem como enquanto discurso; por outro, ele não precisa - nem deve - desprezar a conjuntura da polis em que vive. Logo, considerar a condição estrutural exposta por Lacan (1974/1993), de que todo laço social é segregativo, não equivale a ir ao encontro das políticas segregatórias, cada vez mais instauradas em nosso tempo. Pensando na não conformidade com tal modelo e levando em consideração as críticas (filosóficas e sociais) aos direitos humanos a que nos referimos acima e com as quais concordamos, nossa proposta é ir para além delas e possibilitar a emergência de algo novo, que pode ser construído a partir da psicanálise: o impossível da universalidade desta declaração e a consequente convocação do sujeito do desejo em extimidade ao sujeito de direito.

Em suma, estar advertido deste impossível, mas também reconhecer os escritos e discursos dos direitos humanos enquanto força simbólica e horizonte ético, que representa a própria dimensão do Outro enquanto ordem social, oriunda da fragilidade da condição humana diante dos impasses da existência, condição que Freud denomina de "desamparo fundamental" (Ferreira-Lemos, 2011, p. 102) e, para além disso, arriscar desejar o impossível, o desejo de desejar e o duro desejo de durar, consubstanciado unicamente pela via do sujeito do desejo, em um para além do serviço dos bens e do primum vivere: em outras palavras, a busca por uma vida qualificada. Este caminho nos parece ir de encontro à conformidade com o cenário político em que estamos submersos.

Aqui, talvez seja possível arriscar uma aproximação a uma das enigmáticas passagens de Lacan: em Televisão, ao falar sobre o santo, Lacan afirma que "o santo é o rebotalho do gozo" e que "pouco se lixar para a justiça distributiva é de onde frequentemente ele partiu" (Lacan, 1974/1993, p. 33). Ainda afirma que "o santo não se considera a partir de méritos, o que não quer dizer 
que ele não tenha moral. A única coisa chata para os outros é que não se vê aonde isso leva" (p. 34). Aqui, Lacan articula a noção de ética aristotélica (justiça distributiva) ao serviço dos bens (utilitarismo) ao se referir ao bem atrelado ao gozo e a uma moral não orientada pelo mérito e pela lógica do primum vivere - "quanto mais somos santos mais rimos, é meu princípio, e até mesmo a saída do discurso capitalista —, o que não constituirá um progresso se for somente para alguns" (p. 34). Aqui podemos fazer referência ao Seminário sobre a ética da psicanálise, quando Lacan fala sobre a chegada de Alexandre a Persópolis e de Hitler a Paris: vim liberá-los disto ou daquilo; continuem trabalhando, que o trabalho não pare, o que quer dizer: que esteja claro que não é absolutamente uma ocasião para manifestar o mínimo desejo — "a moral do poder, do serviço dos bens, é - Quanto aos desejos, vocês podem ficar esperando sentados" (Lacan, 1959-60/2008, p. 368).

O sujeito que para a psicanálise surge no intervalo entre dois significantes está nisso que é o que faz o humano advir como o que ele ainda não é (Didier-Weill, 2011). Didier-Weill propõe que esse advir como o que ainda não se é está para além dos diferentes artigos da declaração universal dos direitos humanos: estaria na existência de um artigo único e absoluto, direito do homem que se tornou falante a se reconhecer e a se fazer reconhecer como falante, ao mesmo tempo endividado e libertado pela fala. Este direito subversivo, que remonta à Antígona, está além da lei, não é garantido pela lei:

Este direito é tão mais vivaz e tão mais subversivo, quanto não se deduz não do que está legitimamente escrito, mas de um real que não cessa de não se escrever: por isso, o sujeito está destinado a ser um herético, exposto à possibilidade de inventar, na solidão em que o deixa o fato de não ser garantido pela lei. (Didier-Weill, 2011, p. 6)

O real que não cessa de não se escrever aponta para o objeto da psicanálise, que, como afirmou Lacan em 1966, não é o humano, mas aquilo que lhe falta; não uma falta absoluta, ${ }^{16}$ mas a falta de um objeto (Lacan, 1966/2003a, p. 212), que pode representar um limite epistemológico ao discurso dos direitos humanos na atualidade, uma questão a ser respondida.

\footnotetext{
${ }^{16}$ Grifo nosso. Interessante aqui marcar o fato de não ser uma falta absoluta, mas submetida ao movimento pulsional constante e contingente: falta de $u m$ objeto (qualquer).
} 


\section{ARTIGOS}

\section{Referências}

Arendt, H. (1989). Origens do totalitarismo. São Paulo, SP: Companhia das Letras. Assembleia Geral da ONU (1948). Declaração Universal dos Direitos Humanos $(217$ [III] A). Paris.

Austin, J. L. (1962). How To Do Things With Words. Oxford/New York: Oxford University Press.

Berlinck, M. T. (2008a). A noção de sujeito em psicanálise: um projeto de pesquisa. Psicopatologia fundamental. São Paulo, SP: Escuta.

Berlinck, M. T. (2008b). Insuficiência imunológica psíquica. Psicopatologia fundamental. São Paulo, SP: Escuta.

Chaves, L. de G. M. (1970). Minorias e seu estudo no Brasil. Revista de Ciências Sociais, 1(1), 149-168.

Danto, E. A. (2019). As clínicas públicas de Freud. Psicanálise e Justiça Social, 1918-1938, São Paulo, SP: Perspectiva.

Didier-Weill, A. (2011, jul./dez). Psicanálise e direitos do homem. Trivium, 3(2).

Ferreira-Lemos, P. do P. (2011). Sujeito na Psicanálise: O ato de resposta à ordem social. In M. J. Spink, P. Figueiredo, \& J. Brasilino, J. (Orgs.), Psicologia social e pessoalidade. Rio de Janeiro, RJ: Centro Edelstein de Pesquisas Sociais/ABRAPSO.

Freud, S. (1969). Linhas de progresso na terapia psicanalítica. In Edição Standard Brasileira das Obras Psicológicas Completas de Sigmund Freud (vol. XVII, pp. 168-218). Rio de Janeiro, RJ: Imago. (Trabalho original publicado em $1919[1918])$.

Freud, S. (2011). Psicologia das massas e análise do eu e outros textos. São Paulo, SP: Companhia das Letras. (Trabalho original publicado em 1921).

Hobsbawm, E. (2007). Globalização, democracia e terrorismo. São Paulo, SP: Companhia das Letras.

Hunt, L. (2009). A invenção dos direitos humanos: uma história. São Paulo, SP: Companhia das Letras.

Lacan, J. (1966-67). O seminário. Livro 14. A lógica da fantasia. Inédito.

Lacan, J. (1992). O seminário. Livro 17. O avesso da psicanálise. Rio de Janeiro, RJ: Zahar. (Trabalho original publicado em 1969-70).

Lacan, J. (1993). Televisão. Rio de Janeiro, RJ: Zahar. (Trabalho original publicado em 1974).

Lacan, J. (1998a). O estádio do espelho como formador da função do eu. In Escritos. Rio de Janeiro, RJ: Zahar. (Trabalho original publicado em 1949). 
Lacan, J. (1998b). Kant com Sade. In Escritos. Rio de Janeiro, RJ: Zahar, 1998. (Trabalho original publicado em 1962).

Lacan, J. (1999). O seminário. Livro 5. As formações do inconsciente. Rio de Janeiro, RJ: Zahar. (Trabalho original publicado em 1957-58).

Lacan, J. (2003a). Respostas a estudantes de filosofia. In Outros escritos. Rio de Janeiro, RJ: Zahar. (Trabalho original publicado em 1966).

Lacan, J. (2003b). Radiofonia. In Outros escritos. Rio de Janeiro, RJ: Zahar. (Trabalho original publicado em 1970).

Lacan, J. (2008). O seminário. Livro 7. A ética da psicanálise. (2 ed.) Rio de Janeiro, RJ: Zahar. (Trabalho original publicado em 1959-60).

Lollo, P. (2015). Passagens: transmissão da psicanálise e direitos do homem. Rio de Janeiro, RJ: Contra Capa.

Löwy, M. (2017). O jovem Marx e o furto da madeira. Blog da Boitempo. Recuperado em 26 jan.20, de: <https://blogdaboitempo.com.br/2017/01/30/ michael-lowy-o-jovem-marx-e-o-furto-de-madeira/>.

Marx, K. (2011). O 18 de brumário de Luís Bonaparte. Trad. Nélio Schneider. São Paulo, SP: Boitempo, 2011. (Trabalho original publicado em 1852).

Pereira, M. E. C. (2019, dez.). Projeto de uma (psico)patologia do sujeito (I): redefinição do conceito de psicopatologia à luz da questão do sujeito. Revista Latinoamericana de Psicopatologia Fundamental, 22(4), 828-858. http://dx.doi. org/10.1590/1415-4714.2019v22n4p828.10.

Ramalho, A. M. N. (2009). Neoliberalismo e gozo. In R. C. Vescovi (Org.), A lei em tempos sombrios. Rio de Janeiro, RJ: Companhia de Freud.

Santana, B. W. (2019). Variações do ver: uma articulação entre Psicanálise e Nietzsche. Curitiba, PR: CRV.

Todorov, T. (2010). A conquista da América: a questão do outro. São Paulo, SP: WMF Martins Fontes.

Villey, M. (2005). A formação do pensamento jurídico moderno. São Paulo, SP: Martins Fontes.

Villey, M. (2007). O direito e os direitos humanos. São Paulo: WMF Martins Fontes.

Žizek, S. (2010, jan./jun.). Contra os direitos humanos. Mediações, 15(1) 11-29.

\section{Resumos}

(Notes on correlating psychoanalysis, psychic suffering and human rights: elements for an ethics of the subject) 


\section{ARTIGOS}

This article lists some issues considered crucial for correlating Psychoanalysis and Law, especially the field of Human Rights, taking as an axis of correlation the relationship between the concepts of psychological suffering, helplessness, psychoanalysis ethics and the subject of the unconscious. We suggest reflecting on the statute of law and the social bond based on a shift in its concept of subject and pose the following question: Is the subject of law, based on the rational and conscious human person guided by the humanist tradition and the economy of goods still able to respond to impasses in the field of politics and social ties? Founded on Lacan's assertion that the object of psychoanalysis is not man, but what he lacks - not an absolute lack, but the lack of an object -, this paper uses that statement for its critical approach to the discourse of Human Rights to highlight an epistemological pathway beyond philosophical and social criticism and thus to enable the emergence of something new that can be constructed based on psychoanalysis: the impossible of the universality of Human Rights Declarations and the consequent convocation of the subject of desire in extimity to the subject of law, based on the clinical method as a way of addressing the suffering which humanism, classical ethics and the discourse of Human Rights cover.

Key words: Psychoanalysis, human rights, subject of law, subject of the unconscious

(Notes sur la mise en rapport entre psychanalyse, souffrance psychique et droits de l'homme: elements pour une éthique du sujet)

Cet article recense certaines questions jugées cruciales pour une mise en rapport entre la Psychanalyse et le Droit, en particulier le domaine des Droits de l'Homme, en prenant comme axe de mise en rapport la relation entre les concepts de souffrance psychologique, d'impuissance fondamentale, d'éthique de la psychanalyse et le sujet de l'inconscient. Partant d'une proposition de réflexion sur le statut de droit et le lien social à partir d'un déplacement de sa conception de sujet, se pose la question suivante : le sujet de droit, basé sur la personne humaine rationnelle et consciente, guidée par la tradition humaniste et l'économie des biens est-il encore capable de répondre aux impasses dans le domaine de la politique et des liens sociaux? Partant de l'affirmation de Lacan selon laquelle l'objet de la psychanalyse n'est pas l'homme, mais ce qui lui manque - pas un manque absolu, mais le manque d'un objet -, le présent travail se base sur cette proposition pour esquisser une approche critique $d u$ discours des droits de l'homme dans le but de mettre en évidence un parcours épistémologique au-delà de la critique philosophique et sociale et, ainsi, de permettre l'émergence de quelque chose de nouveau qui puisse être construit à partir de la psychanalyse: l'impossible de l'universalité des Déclarations des Droits de l'Homme et la convocation conséquente du sujet du désir en extimité au sujet du droit à partir de la méthode clinique comme moyen d'aborder la souffrance que recouvrent l'humanisme, l'éthique classique et le discours des Droits de l'Homme.

Mots clés: Psychanalyse, droits de l'homme, sujet de droit, sujet de l'inconscient 
(Notas sobre la articulación entre psicoanálisis, sufrimiento psíquico y derechos humanos: elementos para una ética del sujeto)

En este trabajo se enumeran algunos temas considerados cruciales para una articulación entre el Psicoanálisis y el Derecho, especialmente, en el campo de los Derechos Humanos, tomando como eje de articulación la relación entre los conceptos de sufrimiento psíquico, desamparo fundamental, ética del psicoanálisis y el sujeto del inconsciente. Partiendo de una propuesta de reflexión sobre el estatuto del Derecho y sobre el vínculo social, a partir de un cambio en su concepto de sujeto, se plantea la siguiente pregunta: el sujeto de derecho, basado en la persona humana racional y consciente guiada por la tradición humanista y la economía de bienes, ¿sigue siendo capaz de responder a los contratiempos en el ámbito de la política y de los vínculos sociales? Partiendo de la afirmación de Lacan de que el objeto del psicoanálisis no es el hombre, sino lo que le falta; no una falta absoluta, sino la falta de un objeto, el presente trabajo toma de antemano esta propuesta para transitar por algunas líneas de abordaje crítico del discurso de los Derechos Humanos con el objetivo de resaltar un camino epistemológico que vaya más allá de la crítica filosófica y social y, así, permitir el surgimiento de algo nuevo, que se puede construir a partir del psicoanálisis: la inviabilidad de la universalidad de las Declaraciones de Derechos Humanos y la resultante convocatoria del sujeto del deseo en extimidad al sujeto de derecho desde el método clínico como forma de abordar el sufrimiento cubierto por el humanismo, la ética clásica y el discurso de los Derechos Humanos.

Palabras clave: Psicoanálisis, derechos humanos, sujeto de derecho, sujeto del inconsciente

Citação/Citation: Klajnman, D., \& Brocco, P. (2021, junho). Notas sobre a articulação entre psicanálise, sofrimento psíquico e direitos humanos: elementos para uma ética do sujeito. Revista Latinoamericana de Psicopatologia Fundamental, 24(2), 281-307. http://dx.doi. org/10.1590/1415-4714.2021v24n2p281.4.

Editora/Editor: Profa. Dra. Sonia Leite

Submetido/Submitted: 19.4.2020 / 4.19.2020 Revisado/Revised: 6.9.2020 /9.6.2020

Aceito/Acepted: $28.10 .2020 / 10.28 .2020$

Copyright: (C) 2009 Associação Universitária de Pesquisa em Psicopatologia Fundamental/ University Association for Research in Fundamental Psychopathology. Este é um artigo de livre acesso, que permite uso irrestrito, distribuição e reprodução em qualquer meio, desde que o autor e a fonte sejam citados / This is an open-access article, which permits unrestricted use, distribution, and reproduction in any medium, provided the original authors and sources are credited. 


\section{ARTIGOS}

Financiamento/Funding: Este trabalho não recebeu apoio / This work received no funding.

Conflito de interesses/Conflict of interest: Os autores declaram que não há conflito de interesses. / The authors declare that there is no conflict of interest.

\section{Deborah Klajnman}

Doutora em Psicanálise pela Universidade do Estado do Rio de Janeiro - UERJ (Rio de Janeiro, RJ, Br) com cotutela em psicologia pela Université Côte d'azur - UNICE (Nice, França); Mestre em Clínica e Pesquisa em Psicanálise pela UERJ, especialista em Clínica Psicanalítica pelo Instituto de Psiquiatria da Universidade Federal do Rio de Janeiro UFRJ/IPUB (Rio de Janeiro, RJ, Br) e graduada em Psicologia pela Universidade Federal Fluminense - UFF (Niterói, RJ, Br). Possui experiência em docência, psicologia clínica, saúde mental com ênfase em Psicanálise, psicologia hospitalar e assistência social. Atualmente atende em consultório particular, é professora assistente do departamento de Psicologia e Psicanálise e da especialização em Clínica Psicanalítica da Universidade Estadual de Londrina - UEL (Londrina, PR, Br). Desenvolve pesquisas nos campos da Psicanálise, cujos principais eixos temáticos são: psicopatologia psicanalítica, metapsicologia, direitos humanos, deslocamento forçado e questões migratórias.

Rua Araújo Lima, 47 - Vila Isabel

20541-050 Rio de Janeiro, RJ, Br

deborah.kla@gmail.com

https://orcid.org/0000-0002-2429-5582

\section{Pedro Brocco}

Doutor e mestre em Ciências Jurídicas e Sociais pelo Programa de Pós-Graduação em Sociologia e Direito da Universidade Federal Fluminense - UFF (Niterói, RJ, Br). Advogado. Psicanalista. Membro do Corpo Freudiano Escola de Psicanálise Seção Rio de Janeiro e do Instituto Brasileiro de Direito de Família. Desenvolve pesquisas nos campos do Direito Civil, da Filosofia do Direito, da Antropologia Jurídica, da Ética e da Psicanálise, cujos principais eixos temáticos são: formação da juridicidade moderna e dos Direitos Humanos, História do Direito de Família, Ética e Retórica, conceito de sujeito em Jacques Lacan, conceito de pessoa e de gozo no Direito Civil, Teoria do Direito, conceito de Lei simbólica em Freud e Lacan e conexões entre Direito e Psicanálise.

Rua Pompeu Loureiro, 32 - Copacabana

22061-000 Rio de Janeiro, RJ, Br

pbrocco@uol.com.br

https://orcid.org/0000-0002-0690-6976

This is an open-access article, which permits unrestricted use, distribution,

(cc) BY-NC and reproduction in any medium for non-commercial purposes provided the original authors and sources are credited. 